\title{
Characterization and prediction of household use of solar home system in Leyte Islands, Philippines
}

\author{
Jacqueline M. Guarte ${ }^{1 *}$, Joyce B. Maurillo ${ }^{2}$, and Jenefrey A. Niverba ${ }^{2}$
}

\begin{abstract}
Submitted: 30 July 2019 | Accepted: 18 December 2019

Under the Household Electrification Program of the Philippines' Department of Energy, 530 solar home systems (SHSs) with $30 \mathrm{Wp}$ capacity were installed in individual households in four island barangays (villages) in Leyte and Southern Leyte from 2013 to 2015. Aside from lighting with four LED bulbs, the SHS can also be used to listen to the radio or MP3 player, and charge a mobile phone. This paper examines household use of the SHS thru data collected from 299 beneficiaries interviewed in the period 2017-2018. Results indicated that while all households use the SHS for lighting, its other applications are not utilized as much. A sizable percentage of households are now using only the SHS for lighting in each island barangay. The use of the generator set (for a limited time at night) in partnership with the SHS remains dominant to be able to use the SHS lights longer. Kerosene lamp is now rarely used for lighting except in the absence of a barangay-owned generator set.

With a substantial percentage of households using the SHS for lighting only amidst its other applications, classification trees by island barangay were generated to identify the variables which will explain SHS use with both quantitative and qualitative household characteristics making up the predictor space. Although the classification trees grown are unique to each island barangay, age of the household head and annual household income are the consistent significant predictors (up to the third most important) followed by median age of the household members.
\end{abstract}

Keywords: rural electrification, renewable energy system, nonparametric method, classification trees

'Department of Statistics, Visayas State University, Baybay City, Leyte, Philippines

${ }^{2}$ Renewable Energy Research Center, College of Engineering, Visayas State University, Baybay City, Leyte, Philippines

*Corresponding Author. Address: Department of Statistics, Visayas State University, Baybay City, Leyte, Philippines;Email:jacqueline.guarte@vsu.edu.ph

DOl: $10.32945 /$ atr4217.2020 
Guarte, Maurillo \& Niverba

\section{INTRODUCTION}

Electricity is a basic need of any household, and not having access to it will certainly limit a household's opportunities for improved welfare. Provision of electricity is thereby a global development goal. However, for rural electrification in the Philippines, connection to the grid remains seemingly impossible for isolated and far-flung communities such as island barangays (villages) based on the plans and programs of the electric cooperatives in these areas. That is, the prevailing load requirements of such communities do not economically justify connection to main grids via submarine or overhead cables. Addressing this situation, the country's Department of Energy (DOE) embarked on its Household Electrification Program (HEP) using the photovoltaic (PV) solar home system (SHS) or simply SHS, a renewable energy system, to contribute to the national government's goal of achieving $90 \%$ household electrification in the country by 2017 (DOE 2010). This HEP is similar to India's Remote Village Electrification Program (RVEP) that is being implemented by its Ministry of New and Renewable Energy (MNRE) to electrify remote and inaccessible villages by installing SHSs in all the states (Buragohain 2012). Such solar electrification program is supported then and now by studies in the Philippines and elsewhere that the SHS can be the least cost solution or the most suitable alternative to providing basic electricity services for lighting, communications and other household/community needs in areas with small dispersed populations and remote from the grid and underprivileged rural communities (Meier 2003, Khan et al 2018). Also, the Philippines enjoys good to excellent solar resources throughout the archipelago, even during the rainy season (Meier 2003) due to its location near the Equator. As Kabir et al (2017) point out, SHS stand out above all other options (eg, wind, hydro, geo-thermal, tidal systems) because of their wide-scale potential at latitudes less than $45^{\circ}$ north or south of the Equator where daily solar irradiance is more constant throughout the year.

In collaboration with the then Visayas State University-Affiliated Renewable Energy Center (VSU-AREC), now the Renewable Energy Research Center (RERC), DOE funded the installation of 530 SHSs with $30 \mathrm{Wp}$ capacity in the identified beneficiary households in four selected island barangays in Leyte and Southern Leyte from July 2013 to February 2015. Such SHS unit is designed for poor households with power demand ranging from 10 to $80 \mathrm{Wh}$ per day. With these household beneficiaries as members, solar power associations were established in these island barangays to take charge of the overall operation and maintenance of the SHSs to ensure their viability and sustainability. Each household beneficiary as a member can save for the operation and maintenance of its SHS by paying the membership fee of PHP1,000 and monthly contribution of PHP200 (for three years) mainly for battery replacement.

As a PV system, the SHS does not pollute the environment (as it does not emit gaseous \& liquid pollutants), has zero fuel usage, is noise-free, has low maintenance cost and has a long life of 20 years (Kamalapur \& Udaykumar 2011). As such, it replaces conventional fuels in electricity generation. It is a stand-alone home lighting system composed of a PV or solar module, solar power charge controller, solar battery, wiring and mounting device and loads. The loads of this 30Wp system include: one Light Emitting Diode (LED) light bulb with a rated capacity of $1 \mathrm{~W}$, three LED light bulbs with $3-\mathrm{W}$ capacity, AM/FM radio or MP3 player 
Characterization and prediction of household use of solar

$5 \mathrm{~W}$ capacity, and mobile phone charging with $5 \mathrm{~W}$ capacity. Using the MP3 player and charging a mobile phone cannot be done simultaneously since there is only one USB port.

In an assessment of actual field experience with the SHS in the open literature by Nieuwenhout et al (2001), four main research themes were identified: institutional aspects, financial aspects, technical findings and user experiences. These research themes prevail until the present time with continued lack of detailed information on how SHSs of various capacities are actually used by households in different parts of the world [eg, Bangladesh (Samad et al 2013, Islam et al 2014, Khan \& Azad 2014, Kabir et al 2017, Khan et al 2018); India (Buragohain 2012); Kenya and Uganda (Stojanovski et al 2017); South Pacific (Chow 2010); Thailand (Yaungket \& Tezuka 2013); Zambia (Gustavsson 2007); Zimbabwe (World Bank 2000)]. Addressing this scarcity in the SHS literature would basically require monitoring and evaluation activities through household surveys. Moreover, no statistical analysis on the available data has been made, only summary tables and charts.

As improved electricity access through the SHS provides for more than just home lighting, this paper seeks to know how the household beneficiaries in the four island barangays mentioned use the $30 \mathrm{Wp}$ system in addressing their need for lighting and in utilizing the other applications/benefits provided by such solar electrification. The specific objectives are to:

1.characterize the household beneficiaries' SHS use given their existing sources of energy by island barangay; and

2.identify the variables which will explain household use of the SHS (for lighting only or for lighting and its other uses) by island barangay.

In addition to supplying detailed information on rural household use of the SHS in the Philippines, the results of this paper can generate critical insights toward understanding household use of this $30 \mathrm{Wp}$ system in island communities. These results may also help in improving household use of the SHS as designed for rural areas. These can also contribute in the crafting of SHS policies that will improve the welfare of off-grid rural communities in the Philippines and in other parts of the world.

\section{MATERIALS AND METHODS}

\section{The Study Areas}

The four island barangays under study are all relatively far from the mainland (Figure 1). Barangay Apid, located at $\mathrm{N} 10^{\circ} 32.137^{\prime} \mathrm{E} 124^{\circ} 38.535^{\prime}$, which is part of the municipality of Inopacan, in the province of Leyte, is $14.5 \mathrm{~km}$ away from the mainland of Inopacan. With a total land area of $80 \mathrm{ha}$, it consists of the main island of Apid Proper and the two other islands (sitios or small villages) of Mahaba and Digyo. Barangay Dawahon or Dawahon Island, located at N $10^{\circ} 15^{\prime} 50^{\prime \prime} \mathrm{E} 124^{\circ} 37^{\prime} 2^{\prime \prime}$, is part of the municipality of Bato, also in Leyte. It is $20 \mathrm{~km}$ away from the mainland of Bato. It has a total land area of 20 ha with three sitios. Barangay San Pedro or San Pedro Island, located at N $10^{\circ} 27.656^{\prime} \mathrm{E} 125^{\circ} 13.386^{\prime}$, is part of the municipality of 
Hinunangan in the province of Southern Leyte. It is $3 \mathrm{~km}$ away from the mainland of Hinunangan. It has a total land area of 229 ha covering three sitios. Barangay San Pablo or San Pablo Island, located at N $10^{\circ} 25^{\prime} 31.6^{\prime \prime}$ E $125^{\circ} 13^{\prime} 21.9^{\prime \prime}$, is very near to San Pedro Island, also part of Hinunangan; it is $3.5 \mathrm{~km}$ away from the mainland of Hinunangan. It has a total land area of $40 \mathrm{ha}$ and has three sitios as well. There are 134 households in Apid; 756, in Dawahon; 124, in San Pedro; and 91, in San Pablo. Fishing is the main livelihood in Apid, in San Pedro, and in San Pablo while it is seaweed farming in Dawahon. There are small-scale retail stores in all four island barangays -7 in Apid, 15 in Dawahon, 7 in San Pedro and 4 in San Pablo. The other economic activities in Apid are stripping and handicraft making from the Romblon plant, boat making, copra production, and small-scale piggery. In Dawahon, fishing, sea shells farming, and sea urchin catching are the other means of livelihood. In San Pedro, rice production, copra production, and coconut charcoal production are the other sources of income. In San Pablo, the other economic activities are rice production, copra production, and backyard vegetable growing.

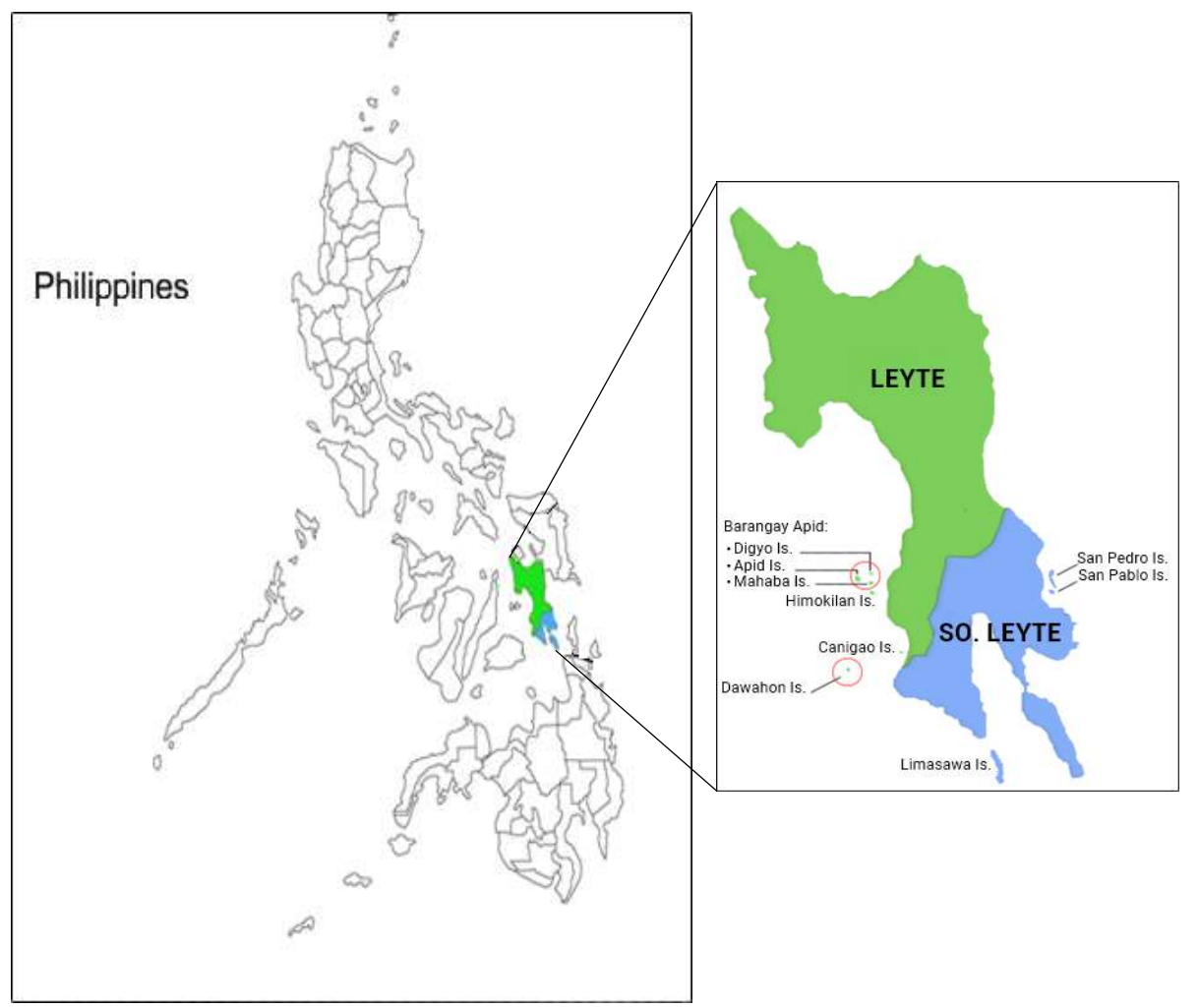

Figure 1. Location of the four island barangays: Apid and Dawahon in Leyte; San Pedro and San Pablo in Southern Leyte, Philippines 
Characterization and prediction of household use of solar

\section{Availability of Generator Sets}

As unelectrified communities, generator sets are available on these island barangays to generate electricity for a limited time at night. Apid has one barangayowned and 9 household-owned generator sets usually operating from $6 \mathrm{pm}$ to $10 \mathrm{pm}$ daily. Dawahon has 31 household-owned generator sets operating from $6 \mathrm{pm}$ to 9 or $10 \mathrm{pm}$ daily. San Pedro has one barangay-owned and 7 household-owned generator sets operating from 6:30pm to 9:30pm daily. San Pablo has one barangay-owned and 9 household-owned generator sets operating in the same period as in Dawahon. However, during the data collection period, the barangay-owned generator set in San Pablo was reported to be no longer operational for three months due to some defect. In these island barangays, households with their own generator sets may allow neighboring households to connect to them for a fee.

\section{Target Populations and Sample Sizes}

The populations of interest in this study are the totality of household beneficiaries with functional SHSs during the conduct of the household surveys in each of the four island barangays (Table 1). This condition was imposed since some households were no longer using their SHS units due to some operational problems. A complete enumeration was planned for Apid, San Pedro and San Pablo given their household population sizes. During the conduct of the household surveys; however, some SHS beneficiaries were not around. Hence, the less than $100 \%$ survey coverage in these island barangays with the numbers of households surveyed were as follows: 55 in Apid, 106 in San Pedro, and 41 in San Pablo (Table 1). Dawahon, having the most numerous household beneficiaries and being perceived to be relatively homogeneous with respect to household characteristics related to SHS use, has a sampling coverage of less than $50 \%$ with 97 households surveyed (Table 1 ).

Table 1. Population and sample sizes by island barangay in Leyte and Southern Leyte, Philippines

\begin{tabular}{|c|c|c|c|c|}
\hline Province & Island Barangay & $\begin{array}{c}\text { Total No. of } \\
\text { Household } \\
\text { Beneficiaries of } \\
\text { Solar Home System } \\
\text { (SHS) }\end{array}$ & $\begin{array}{c}\text { Total No. of } \\
\text { Household } \\
\text { Beneficiaries } \\
\text { with Functional } \\
\text { SHSs During the } \\
\text { Household } \\
\text { Surveys (N) } \\
\end{array}$ & $\begin{array}{l}\text { Number of } \\
\text { Household } \\
\text { Beneficiaries in } \\
\text { the Sample } \\
(\% \text { of } \mathrm{N})\end{array}$ \\
\hline Leyte & $\begin{array}{l}\text { Apid } \\
\text { Dawahon Island }\end{array}$ & $\begin{array}{r}76 \\
277\end{array}$ & $\begin{array}{r}60 \\
274\end{array}$ & $\begin{array}{l}55(91.7) \\
97(35.4)\end{array}$ \\
\hline $\begin{array}{l}\text { Southern } \\
\text { Leyte }\end{array}$ & $\begin{array}{l}\text { San Pedro Island } \\
\text { San Pablo Island }\end{array}$ & $\begin{array}{r}114 \\
53\end{array}$ & $\begin{array}{r}107 \\
45\end{array}$ & $\begin{array}{c}106(99.1) \\
41(91.1)\end{array}$ \\
\hline
\end{tabular}


Guarte, Maurillo \& Niverba

\section{Variables Measured and Data Collection}

A questionnaire was constructed consisting of both open-ended and closed questions to gather data on relevant household characteristics and on how the household beneficiary uses the SHS. The household variables measured included the SHS load utilization, parts of the house lighted and the corresponding SHS bulbs used. As there was no available literature explaining household use of the SHS (for lighting only or for lighting \& its other uses), predictors were identified from the household characteristics measured in this study. These included household size and whether the household uses a generator set for electricity or is connected to one. The following household characteristics gathered were sources of additional predictors: age of the household head and of all the other members of the household (years), whether the household uses kerosene for lighting and average household income for each month (PHP). Following the prepared questionnaire, household respondents in Apid, in San Pedro and in San Pablo were interviewed in the third and fourth quarters of 2017 while those in Dawahon were interviewed in the first quarter of 2018.

\section{On the Selected Predictors of Household Use of the SHS}

Exploratory data analysis (EDA) prior to estimation of model/classification tree was undertaken to examine the relationship between each of the six predictors and the binary response variable (type of household use of the SHS) in the four island barangays.

Annual Household Income. Sample households using the SHS for lighting only have the higher median annual household income in all the four island barangays: PHP82,480 against PHP53,600 in Apid; PHP72,000 against PHP62,400 in Dawahon; PHP36,000 against PHP24,000 in San Pedro; and PHP78,000 against PHP36,000 in San Pablo. Higher income households tend to use the SHS for lighting only to ensure longer use of the SHS lights as they can well afford to use the generator set for their other energy needs. Annual household income may then be able to explain type of household use of the SHS in these island barangays.

Household Size. Sample households using the SHS for lighting only tend to be larger in Apid and in Dawahon (5 against 4) while they tend to be smaller in San Pedro (2 against 3), based on the median. In San Pablo, the median household sizes are the same (both 4). It is reported that, in the small island of Vanuatu in the South Pacific Ocean, because of the relatively large number of people in any one household, most will have all the SHS lights put on at the same time since every lighted room will be occupied (Chow 2010). This common usage pattern supports a household's bias toward using the SHS for lighting only if it is large. On the other hand, in a study of SHSs sold to households under a micro-finance scheme in Bangladesh, Islam et al (2014) concluded that small families mostly use 10 to $20 \mathrm{Wp}$ while big families basically use $65 \mathrm{Wp}$ or $85 \mathrm{Wp}$. This implies that bigger households also tend to use more energy and/or more varied applications of the SHS compared to smaller households. Thus, household size is a potential predictor of type of household use of the SHS, in general.

Use of Generator Set for Electricity (Yes, No). In Apid, San Pedro, and San Pablo, households tend to use the SHS for lighting and its other uses regardless of whether they are connected to a generator set or not $(70.6 \%$ if connected $\& 57.1 \%$ if 
Characterization and prediction of household use of solar

not, $67.9 \%$ if connected \& $69.8 \%$ if not \& $87.5 \%$ if connected \& $66.7 \%$ if not, respectively). In Dawahon, households tend to use the SHS for lighting only whether they are connected to a generator set or not ( $52.5 \%$ if connected $\& 61.1 \%$ if not). Both situations indicate that use of generator set may still be a likely predictor of type of household use of the SHS in these island barangays due to the marked dominance of one type of SHS use over the other, particularly in San Pablo.

Use of Kerosene for Lighting (Yes, No). In Apid and in San Pablo, most households use the SHS for lighting and its other uses regardless of kerosene use for lighting (66.7\% if using \& $72.4 \%$ if not using in Apid; $85.7 \%$ if using \& $65.0 \%$ if not using in San Pablo). It is still likely for this variable to be a good predictor of type of household use of the SHS in the said island barangays due to the substantial dominance of one type of SHS use over the other. In Dawahon, households tend to use the SHS for lighting only if they do not use kerosene for lighting (56.5\% if not using \& $40.0 \%$ if using) while they tend to use the SHS for lighting and its other uses if they do (60.0\% if using \& $43.5 \%$ if not using). It is the exact opposite in San Pedro-households tend to use the SHS for lighting and its other uses if not using kerosene for lighting $(69.6 \%$ if not using $\& 33.3 \%$ if using) and for lighting only if they do $(66.7 \%$ if using $\& 30.4 \%$ if not using). These indicate that use of kerosene for lighting may be able to predict how the households use the SHS in Dawahon and in San Pedro.

Median Age of Household Members. In Apid, Dawahon, and San Pablo, households using the SHS for lighting only have younger members based on the median (24 against 28 years, 22 against 28 years \& 17.5 against 30 years, respectively). In San Pedro, households using the SHS for lighting only tend to have older members (41 against 31.5 years). Hence, median age of the household members may play an important role in explaining household use of the SHS in all four island barangays.

Age of Household Head. In Apid, Dawahon, and San Pedro, households using the SHS for lighting only tend to have older household heads based on the median (49 against 45 years, 50.5 against 43 years \& 62.5 against 51 , respectively). One explanation for this is that an older person may not use the SHS for its other applications for fear of destroying it as shared by some respondents. In San Pablo, it appears to be the opposite with 39 against 46 years. Hence, age of the household head may more likely be an important predictor of type of household use of the SHS in these island barangays.

\section{Classification and Prediction of Household Use of the SHS}

With the response or output variable being binary--type of household use of the SHS (whether the household beneficiary is using the SHS for lighting only or for lighting \& its other uses), classification trees were used in this study to classify and predict the type of household use of the SHS by island barangay using the six predictors identified. The kind of information provided by the estimated model/classification tree in addressing the paper's second objective is the underlying reason for this choice. Specifically, in this paper, the estimated model presents several pathways or sequences of decision rules for a household to be classified or predicted as using the SHS for lighting only or for lighting and its other uses, respectively. These sequences of decision rules identify the values or 
categories of the significant predictors that classify or predict the household as using the SHS for lighting only or for lighting and its other uses.

Introduced in the mid 1980s by Breiman, Friedman, Olshen and Stone (James et al 2013), tree-based classification models have been used extensively in a wide variety of fields and have been found especially useful in biomedical and genetic research, marketing, political science, speech recognition and other applied sciences (Izenman 2008). Classification trees were used in analyzing suicidal tendencies among the youth in the Philippines (Villejo 2015). Also, classification trees were used in identifying factors influencing credit card ownership (Retumban 2015). The application in this paper may provide another perspective on the utility of such statistical technique.

Izenman (2008) points out that a classification tree is both a nonparametric (ie, distribution-free) statistical method and a supervised statistical learning technique (ie, a tool for understanding data which involves building a statistical model for predicting or estimating an output based on one or more inputs). It can be seen as an alternative to regression analysis since it is used to predict a categorical or qualitative output or response based on a set of predictors. The predictors can be both quantitative and qualitative variables and the sample size can be small. The estimated model is a set of rules represented by a tree diagram or decision tree which shows the stratification of the predictor space into a number of simple regions. Such process also leads to segmentation of the household population in this study as it allows for the identification of households who are likely to be this type of SHS user or the other in each island barangay.

It is noted here that while "tree-based methods are simple and useful for interpretation, they are not competitive with the best supervised learning approaches in terms of prediction accuracy" (James et al 2013). However, these other approaches involve producing a large number of trees (as huge quantities of data are involved) and then combining them, at the expense of some loss in interpretation. Moreover, if the data set is large enough, it is now a common practice to use a random mechanism to separate the data into three non-overlapping and independent sets: a learning or training set (about $50 \%$ of the data), a validation set $(25 \%)$ to be used for model selection and assessment of competing models, and a test set $(25 \%)$ to be used for assessing the performance of a completely specified final model (Izenman 2008). The data set may just be partitioned into two-training set and test set as used by Villejo (2015) with 18,680 cases and Retumban (2015) with 995 cases. Since relatively small data sets are analyzed in this study (given that the household populations involved are not large), the use of classification trees without having to separate the data into such sets is taken to be appropriate and sufficient for the purpose. This was illustrated by Izenman (2008) with the Cleveland heart-disease data of 296 patients to classify and predict the health status of the patient [classified as either healthy (160) or with heart disease (136)].

A classification tree is made up of internal nodes (points where the tree separates or splits into two branches) and terminal nodes or endpoints. James et al (2013) explain that the idea is to predict that each observation belongs to the most commonly occurring class of observations in the region to which it belongs. Consequently, such prediction is typically made using the mode of the observations in the region to which it belongs. "In interpreting the results, the interest is often not only in the class prediction corresponding to a particular terminal node region, but also in the class proportions among the observations that fall into that region," 
Characterization and prediction of household use of solar

James et al (2013) emphasize. Hence, the class proportions (in percent) are presented, instead of the modal class, in the terminal nodes of the classification trees generated in this paper.

The task of growing a classification tree is undertaken through an algorithm known as recursive partitioning where a decision tree is constructed by the splitting of each node (or parent node) into two daughter (or child) nodes (Izenman 2008). The algorithm generates a classification tree by sequentially doing binary splits on the response data starting from the root node (which consists of the entire data set for an island barangay in this paper). Specifically, the algorithm asks a sequence of hierarchical Boolean questions on the value of a single predictor (eg, is $X_{i} \leq \theta_{j}$ ? where $\theta_{j}$ is a threshold value). Observations satisfying the condition for the predictor drop down to one of the two daughter nodes while the remaining observations not satisfying the condition drop down to the other daughter node. The sequence terminates in a prediction of the class. The two functions preferred as measures of goodness of a split, which are also the usual default in statistical software, can be presented in the following manner (Villejo 2015). Let $\pi_{1}, \pi_{2}, \ldots, \pi_{K}$ be the $K \geq 2$ classes and let $p(k \mid \pi)$ be an estimate of $P\left(X \in \pi_{k} \mid \tau\right)$, the condition -al probability that an observation $X$ is in $\pi_{k}$ given that it falls into node $\tau$. The first is the entropy function defined by

$$
i(\tau)=-\sum_{k=1}^{K} p(k \mid \tau) \log [p(k \mid \tau)],
$$

which reduces to a function of the following form when there are only two classes (as in this paper),

$$
i(\tau)=-p \log (p)-(1-p) \log (1-p),
$$

while the second is the Gini diversity index,

$$
i(\tau)=\sum_{k \neq k^{\prime}} p(k \mid \tau) p\left(k^{\prime} \mid \tau\right)=1-\sum_{k}[p(k \mid \tau)]^{2}
$$

which reduces to $i(\tau)=2 p(1-p)$ if there are only two classes. Splits are found that maximize the homogeneity of child nodes with respect to the value of the response variable. As shown, the Gini index is based on squared probabilities of membership for each category of the response variable. It reaches its minimum (zero) when all cases in a node fall into a single category. These two measures of goodness of a split do not significantly differ for practical purposes as they are quite similar numerically as measures of node purity (James et al 2013). The smaller their values the better the classification tree since such values indicate that a node contains predominantly observations from a single class. As Villejo (2015) pointed out, the class associated with a terminal node corresponds to the class where the majority of the observations belong. This is called the plurality rule. Thus, at each terminal node, a household is classified or predicted to belong to whichever is the dominant class (based on the percentages) in this paper.

To generate classification trees in practice, one needs to choose a growing method from several available in a statistical software package. The growing method used in this paper is CRT (Classification \& Regression Trees) using the Statistical Package for the Social Sciences (SPSS) Version 22. This growing method splits the data into segments that are as homogeneous as possible with respect to the response variable. The Gini diversity index, the default measure of 
node purity, was used in this paper. In SPSS, one needs to specify the maximum tree depth (desired number of levels or height of the tree (in this paper, the default 5 was used), minimum number of cases in parent node (in this paper, 4 to10 cases/households were tried) and minimum number of cases in child node (in this paper, 2 to 5 cases/households were tried). Incomplete or lacking data on the predictor variables can limit the predictive ability of the estimated model. In this regard, the number of sample households included in generating the classification trees or estimated models was reduced from 55 to 32 in Apid, 106 to 85 in San Pedro and 41 to 27 in San Pablo to have a complete data set on all the six predictors used. CRT ranks each significant predictor or independent variable according to its importance in the estimated model. This is shown by the order of appearance of the significant predictors in the classification tree-the first appearing from the top (which is the first significant predictor used by the estimated model to classify the data) is the most important (ie, has the most significant association with the binary response variable), and so on.

In using CRT, there are three stopping criteria reported by SPSS to serve as bases in selecting the "best" classification tree or estimated model for a given data set. The first is the overall correct classification rate which is the percentage of correctly classified cases (households) in the data set ( $p$, expressed in percent); this should be the highest possible, close to $100 \%$. The second is the risk estimate which is the proportion of cases incorrectly classified in the data set $(1-p=q)$. The third is the estimate of the standard error of the risk estimate $\widehat{S E}(q)$. Given a data set of size $n$ the default estimator used is

$$
\widehat{S E}(q)=\sqrt{\frac{p q}{n}}
$$

which is that under simple random sampling when the population size is large. Both the risk estimate and its standard error estimate should be the lowest possible, close to zero, with the latter becoming stable or unchanging. For this paper, the reported standard error estimates were recomputed considering that the data sets used came from populations that cannot be considered large. Using the appropriate estimator when the population size $N$ cannot be considered large will avoid overestimating such error. This estimator is given as

$$
\widehat{S E}(q)=\sqrt{\frac{p q}{n-1}\left(1-\frac{n}{N}\right)}
$$

by Lohr (2010). The standard error estimates computed from (4) and (5) are close whenever the sampling fraction, $\frac{n}{N}$, is small, as reflected in (5).

\section{RESULTS AND DISCUSSION}

\section{Household Use of the Solar Home System Given the Types of Loads}

With the SHS loads, consumption of energy from the SHS has three alternative uses besides lighting (Figure 2). Based on the sample households, all household beneficiaries use the SHS for lighting (Figure 3). Through the SHS, there were household beneficiaries experiencing light from an electric bulb for the first time as they were using kerosene lamp and/or candle before. This can be expected to be at most 24\% in Apid, $2 \%$ in Dawahon, $16 \%$ in San Pedro, and 2\% in San Pablo. Lighting 
Characterization and prediction of household use of solar

the house using the SHS is not limited to night time only in these island barangays. The SHS is also used for lighting during the day when the house is located in a shaded area, or when houses are built very close to each other, or when there is only a small window in the house.

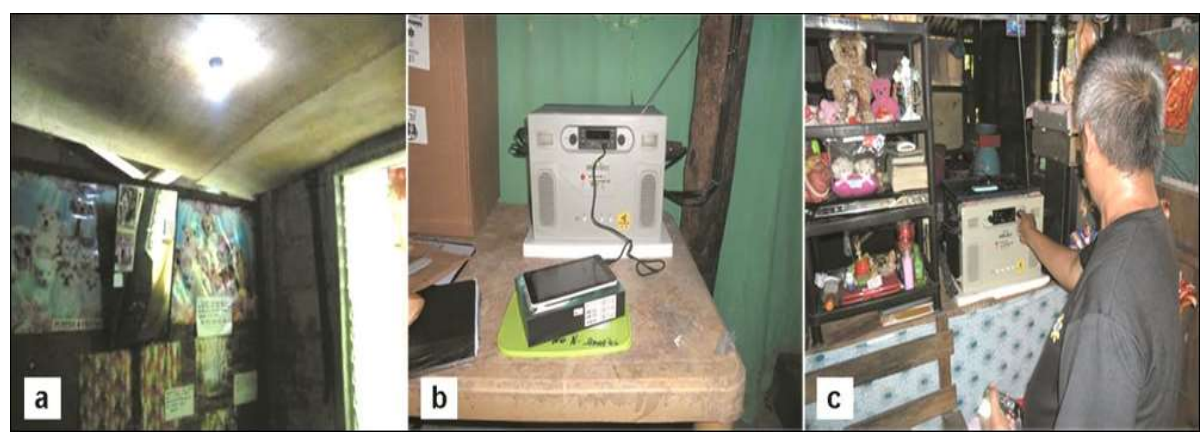

Figure 2. Uses of the solar home system in the household: (a) lighting, (b) charging of mobile phone and (c) listening to the radio or MP3 player
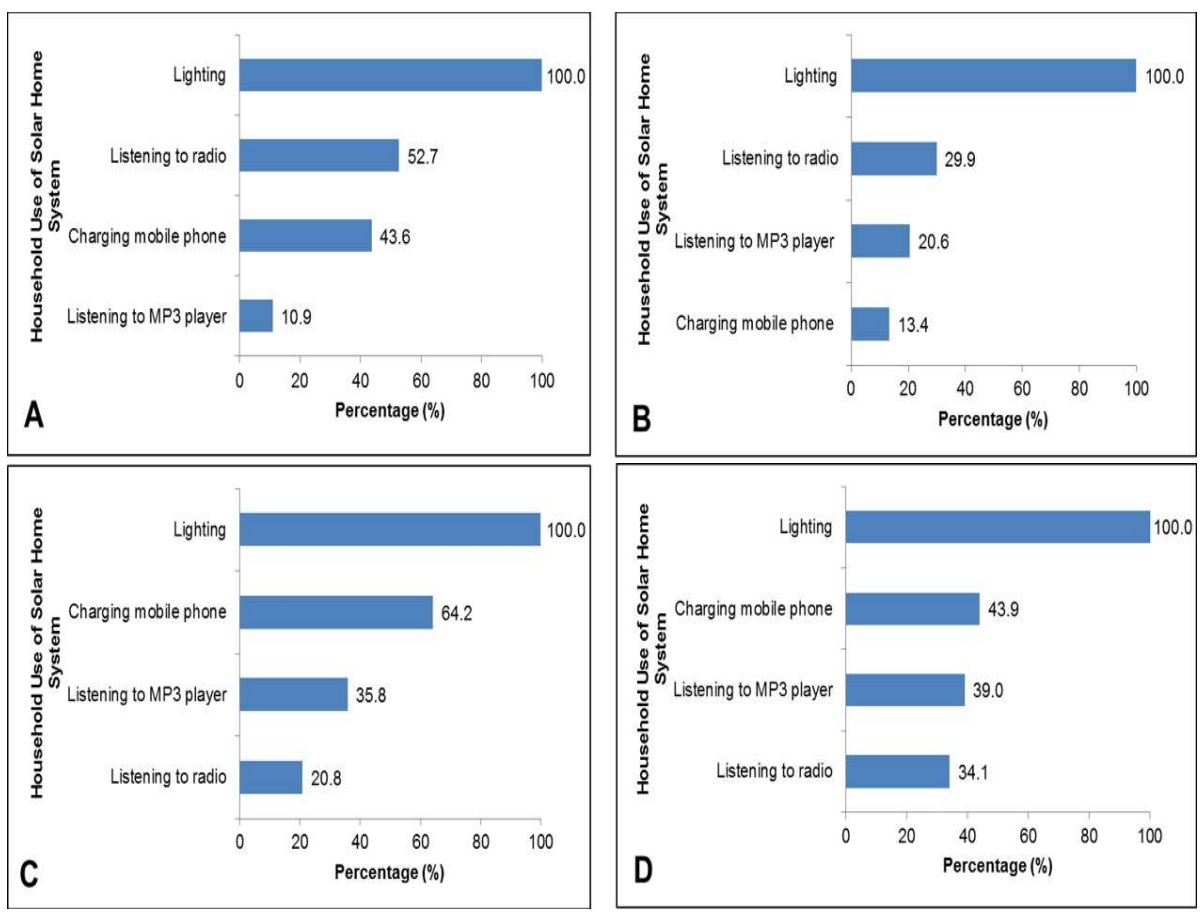

Figure 3. Household use (multiple response) of the solar home system in the four island barangays (A. Apid; B. Dawahon; C. San Pedro; D. San Pablo)

Using the SHS to listen to the radio comes second in Apid and Dawahon while it comes fourth in San Pedro and in San Pablo (Figure 3). It should be noted that the SHS was not used to power radios, for the most part, as indicated by the percentage of sample households using, ranging from 21 to $53 \%$ in the four island barangays. This is similar to the observation on the early adoptors of SHSs in two 
off-grid markets in Africa (Stojanovski et al 2017). Charging the mobile phone comes second in San Pedro and San Pablo while it comes third and fourth in Apid and in Dawahon, respectively. The first two dominant SHS applications observed in San Pedro and in San Pablo is similar to SHS use in the rural areas of Bangladesh but with a 50Wp system (Kabir et al 2017). While listening to the MP3 player may be done most likely by only a few (about 11\%) in Apid, it appears to be done by more than one-fifth of the household populations in Dawahon, in San Pedro, and in San Pablo. With only one USB port for mobile phone charging and using the MP3 player, charging the mobile phone appears to be more needed by the households except in Dawahon. This can be attributed to the continued use of the generator set for mobile phone charging in Dawahon to be able to use the SHS longer for lighting.

\section{Different Ways Households Use the Solar Home System}

Considering all possible ways of using the SHS with the four types of loads, the household beneficiaries in Apid have 7 ways while those in the other three island barangays have 8 ways (Figure 4). One can expect that more than half of the household beneficiaries in Dawahon use the SHS for lighting only while less than $35 \%$ do so in the other three. That is, most household beneficiaries in Dawahon appear to ignore the other applications of the SHS with listening to the radio aside from lighting as the second dominant SHS load utilization not even reaching $20 \%$. In Apid, the other important ways of using the SHS are lighting coupled with listening to the radio and charging the mobile phone, and lighting with just listening to the radio. In San Pedro, about one-fourth of the households are likely to use the SHS for both lighting and mobile phone charging while close to one-fifth can be expected to use the SHS not only for these applications but also for listening to the MP3 player as well. On the average, mobile phone charging using the SHS is done thrice a week at three hours each time in San Pedro, mostly during the day. In San Pablo, using the SHS for charging the mobile phone aside from lighting is not even common. In Apid, Dawahon, and San Pablo, mobile phone charging is usually done using the generator set (at night) and is not done daily with the type of mobile phones commonly used. In the four island barangays, the SHS is typically used mainly for lighting at night and for its other uses at day time. This is actually a good practice as "any load demand other than lighting should be strongly encouraged to be used only during the day time when there is sunlight on the panel; this relieves unnecessary current loading on the battery and will help prolong its lifespan" as pointed out by Chow (2010).

Household beneficiaries may be using the SHS less for its other applications for several reasons: to conserve solar energy for lighting or the concerned loads (eg, radio \& MP3 player) are not functional. Also, their daily routine may not include such activities as listening to the radio or listening to music while staying at home. Another reason is that household beneficiaries continue to use their dry cell batteryoperated radio as they can bring this with them anywhere, particularly when they need to work outside the house for a long period of time. These household beneficiaries are no different from many SHS users in other developing countries whose main reason to continue using dry cell batteries for radio is that they value highly being able to use the radio at different locations, including outside the house (Nieuwenhout et al 2000). As it is, there is lack of awareness that "SHSs are a much more environmentally friendly source of electricity than dry cell batteries, which contain highly toxic substances and often end up as "toys" in the hands of children 
Characterization and prediction of household use of solar

or are disposed of in such a way that they pollute sources of drinking water or the soil in livestock grazing areas" (Bierman et al 1992). Only a minority (about five to twelve percent) may use all four types of SHS loads in each island barangay.
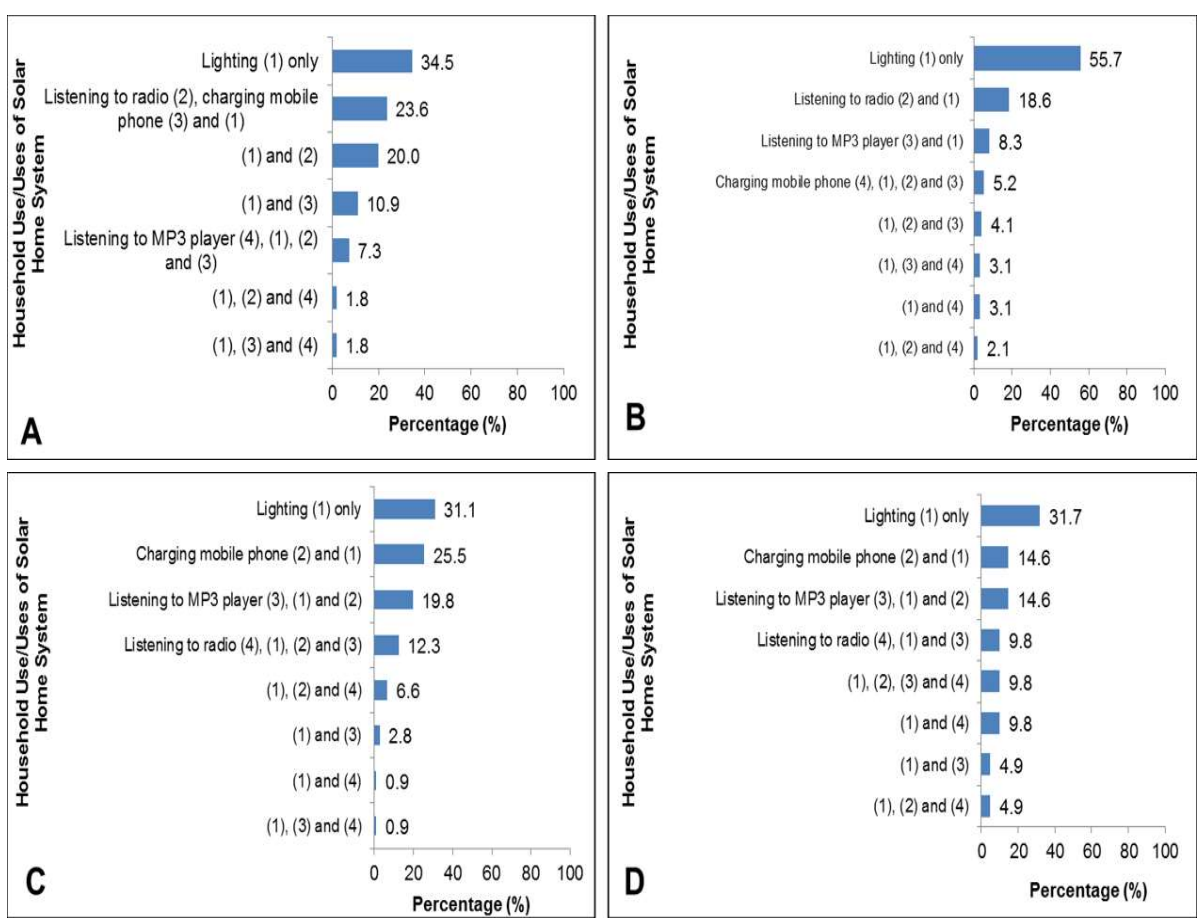

Figure 4. All possible ways households use their solar home systems in the four island barangays (A. Apid; B. Dawahon; C. San Pedro; D. San Pablo)

\section{Household Use of the Solar Home System for Lighting Given Other Sources}

The availability of the SHS changes the composition of a household beneficiary's energy consumption for lighting. Prior to the SHS installations in the island barangays, majority of the households in Apid (about 67\%), San Pedro (about $51 \%$ ), and San Pablo (about 72\%) were using both the generator set and kerosene lamp for lighting. In Dawahon, households using both the generator set and kerosene lamp dominated (about 40\%) followed closely by those using the kerosene lamp only (about 38\%). A sizable percentage of households were using the generator set only in all four island barangays: Apid (about 29\%), Dawahon (about 21\%), San Pedro (about 25\%), and San Pablo (about 15\%). With the advent of the SHS, there are now households who are solely dependent on the SHS for their lighting needs (Figure 5). The largest percentage (about 45\%) is expected to be in San Pedro with the smallest (about 18\%) in San Pablo. In using the SHS, a household is able to save on the cost of electricity from a generator set. However, the biggest (about 48\%) group in San Pedro is still dependent on both the SHS and the generator set for lighting. These households first use the SHS as early as $5 \mathrm{pm}$ then some switch to the barangay-owned generator set once it becomes available (operating from 6:30pm until 9:30pm). Others continue using the SHS together with the 
generator set for continuous lighting of some parts of the house as they can only light one bulb and operate one electrical appliance with the generator set. The SHS is used until early morning (instead of the kerosene lamp) once the generator set is put off.

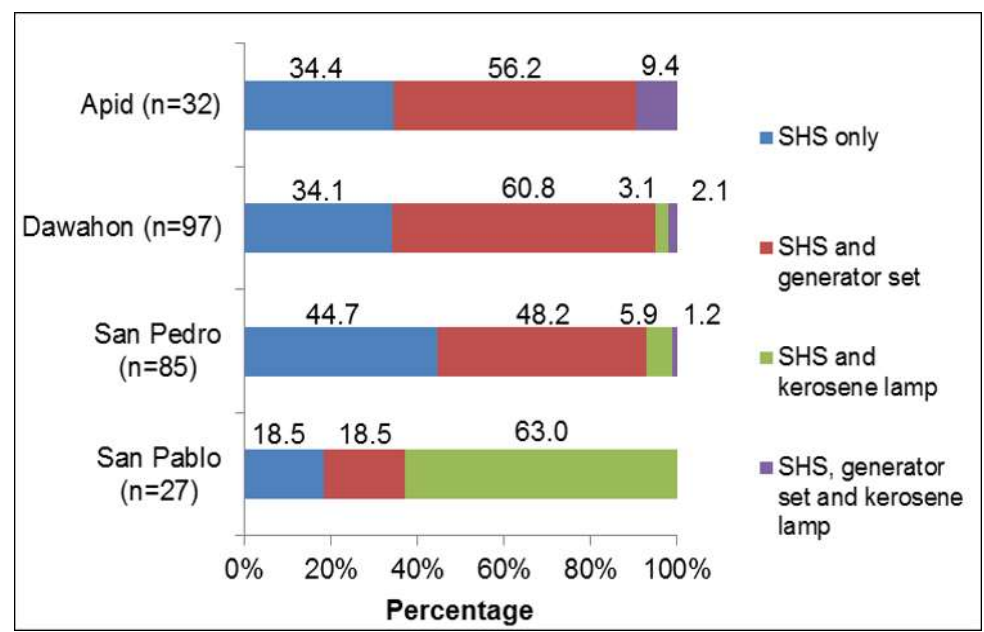

Figure 5 . Household sources of lighting in the four island barangays

In Apid and Dawahon, most (about $56 \% \& 61 \%$, respectively) households are using the generator set alongside the SHS. In Dawahon, most households are still connected to a generator set to be able to watch television programs and run electrical appliances at night. However, there are households in Dawahon using the SHS for lighting only who are no longer connected to a generator set to save on costs.

In San Pablo, majority (about $63 \%$ ) of the households have not given up using kerosene for lighting despite having the SHS. This can be partly explained by the absence of the barangay-owned generator set (which became defective). That is, households are using the kerosene lamp alongside the SHS in lieu of the generator set. The use of kerosene for lighting, however, is already rare in Apid, Dawahon, and San Pedro. One important reason is the realization that the kerosene lamp is a fire hazard (more than a health risk), especially in Dawahon where most houses are built with practically no space at all in between. Indeed, there have been numerous reports of deaths in fires caused by kerosene lamps and these could be most frequent among the poorest families where home-made kerosene lamps are reported (Meier 2003).

It is also important to note that household dependence on the SHS in combination with the generator set and kerosene for lighting may have to do with the number of SHS LED bulbs in use (ie, two to three bulbs are in use since some are busted or some are being kept as reserve) and the parts of the house that need to be lighted at night. When only one or two SHS bulbs are used, these are usually placed at the central part of the house where the available light can be widely distributed throughout the house. A kerosene lamp is usually placed in the bedroom for overnight use-until dawn (5am) or early morning (6am). It may also be placed in the kitchen where dim light is sufficient after the evening chores are done. 
Characterization and prediction of household use of solar

\section{Parts of the House Most Commonly Lighted Using the Solar Home System}

During the SHS installations by the technicians of the SHS suppliers, the four SHS LED bulbs were also installed in the four parts or locations inside and outside the house as determined by the household beneficiary. It should be noted that there are four light bulb switches (contained in the SHS battery box kit) designated as 1,2, 3 and 4 with the first three for the three $3 \mathrm{~W}$ bulbs and the last one for the only $1 \mathrm{~W}$ bulb. With the four SHS LED bulbs ready for use right after the SHS installation, only very few (most likely 1 in 50) household beneficiaries may have decided not to use all four bulbs, so they can keep at least one for future replacements. In deciding on the number of SHS bulbs to use, these households also decided on which parts of the house should be lighted. For the majority who used all four bulbs right away, having at least one busted bulb sooner or later led to the household deciding which parts of the house will remain lighted or no longer lighted for the meantime while waiting for bulb replacement. That is, the remaining functional bulbs were either maintained where they were or the busted bulb was replaced by a functional one resulting to a certain part of the house no longer lighted.

The typical house of an SHS beneficiary in Apid, San Pedro and San Pablo has the following parts or sections: living room, kitchen, bedroom, and comfort room. The living room and kitchen are also used as the dining area in most of these households. The comfort room is either inside the house or in a separate structure outside the house. A flashlight (mostly the rechargeable solar type) is usually used when using the comfort room at night. On the other hand, the typical house of an SHS beneficiary in Dawahon is a two-storey structure with the living room and kitchen on the first level and the bedroom and another "living room" area (near the stairs) upstairs where household members would come together in the evening. Not all households have their own comfort rooms as there are also those constructed for public use. The bedroom, kitchen, living room and "outside the house" (front corner of the house where the main door is located) are the most common parts lighted when all four bulbs are used (Table 2 ). These were the same parts of the house prioritized for the location of the four bulbs during the SHS household installations. The practice of having one SHS bulb outside the house put on overnight can be considered most needed in Dawahon followed by Apid. This appears to be not as necessary in San Pedro and in San Pablo, reflecting the varying levels of safety perceived in these island communities. In other parts of the world, SHS users are also observed to put on at least one SHS bulb overnight - at the porch - for security reasons, highlighting the end-user perception of electric lights as desirable security systems (Stojanovski et al 2017).

When one SHS bulb is busted or three SHS bulbs are in use, the bedroom is the most common part of the house that is not lighted by an SHS bulb in Apid and Dawahon households. In San Pedro and San Pablo, the outside of the house is no longer lighted. With only two SHS bulbs in use, the bedroom and the kitchen are both most commonly lighted in Apid and San Pablo households. In Dawahon and San Pedro, the living room is the most commonly lighted along with the outside of the house and the bedroom, respectively. When only one SHS bulb remains functional, the living room is the most commonly lighted by households in Apid and in San Pedro while it is the kitchen in Dawahon. In San Pablo, the living room and the bedroom are equally the most commonly lighted parts of the house when only one SHS bulb is in use. 
Guarte, Maurillo \& Niverba

Table 2. Most commonly lighted parts of the house by number of solar home system LED bulbs in use and island barangay

\begin{tabular}{ccccc}
\hline \multirow{2}{*}{$\begin{array}{c}\text { Number of LED } \\
\text { Bulbs in Use }\end{array}$} & Apid & Dawahon & San Pedro & San Pablo \\
\cline { 2 - 4 } 1 & Living room & Kitchen & Living room & $\begin{array}{c}\text { Living room and } \\
\text { bedroom }\end{array}$ \\
\hline 2 & $\begin{array}{c}\text { Bedroom and } \\
\text { kitchen }\end{array}$ & $\begin{array}{c}\text { Living room and } \\
\text { outside the house }\end{array}$ & $\begin{array}{c}\text { Bedroom and } \\
\text { living room }\end{array}$ & $\begin{array}{c}\text { Bedroom and } \\
\text { kitchen }\end{array}$ \\
\hline 3 & $\begin{array}{c}\text { Kitchen, living room and outside the } \\
\text { house }\end{array}$ & Bedroom, kitchen and living room \\
\hline 4 & \multicolumn{2}{c}{ Bedroom, kitchen, living room and outside the house } \\
\hline
\end{tabular}

\section{Classification Tree on Type of Household Use of SHS in Apid}

In Apid, the complete data set ( $\mathrm{n}=32$ ) has households using the SHS for lighting and its other uses dominating (71.9\%) over those using the SHS for lighting only (28.1\%). At this root node, a relatively homogeneous population is indicated. The best classification tree or estimated model produced has a tree depth of 5 (Figure 6) with a $93.8 \%$ overall correct classification rate (risk estimate $=0.063$ with standard error estimate $=0.0297$ ). Note that with the three significant predictors identified by the estimated model (age of household head, median age of household members and annual household income), there are 6 splits and 7 terminal nodes in this tree. There are 3 paths or sequences of splits for a household to be classified or predicted as using the SHS for lighting only, and 4 paths for a household to be classified or predicted as using the SHS for lighting and its other uses.

Now, the first significant predictor used by the estimated model to classify the data is age of the household head, indicating that it is the most important predictor of type of household use of the SHS in Apid among the three significant predictors identified. This is followed by the median age of the household members and annual household income, as the second and third most important predictors. The expected individual results from EDA on these three significant predictors as each relate to type of household use of the SHS are not directly translated in the estimated model as it is now the interplay among these three predictors that is shown in classifying the household into one of two categories of the response variable.

It is indicated in the estimated model (Figure 6) that if the household head is not older than 34 years, then the household is classified as using the SHS for lighting only. If the household head is older than 34 years, the median age of the household members is more than 38.5 or 38 years, and the annual household income does not exceed PHP46,820, then the household is classified as using the SHS for lighting and its other uses. However, if the annual household income exceeds PHP46,820, the household is classified as using the SHS for lighting only. On the other hand, if the median age of the household members does not exceed 38.5 or 38 years and the annual household income does not exceed PHP55,250, then the household is classified as using the SHS for lighting and its other uses. Also, if the annual 
Characterization and prediction of household use of solar

household income exceeds PHP55,250 and the median age of the household members exceeds 26 years, the household is classified as using the SHS for lighting and its other uses. On the other hand, if the median age of the household members does not exceed 26 years but more than 21.5 or 22 years, then the household is classified as using the SHS for lighting only. If the median age of the household members is not more than 21.5 or 22 years, then the household is classified as using the SHS for lighting and its other uses.

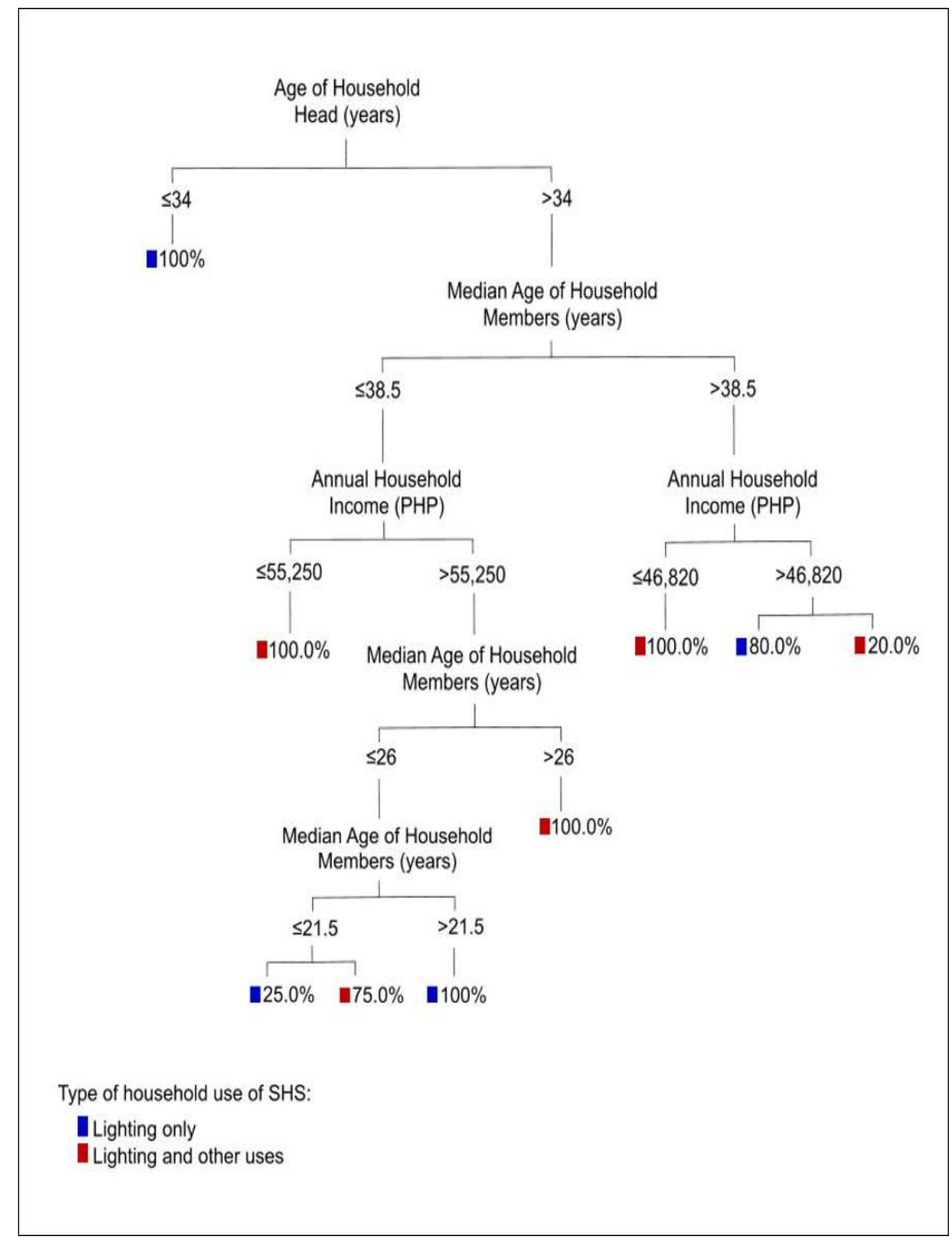

Figure 6. Classification tree on type of household use of the solar home system in Barangay Apid, Inopacan, Leyte 
Characterization and prediction of household use of solar

household income exceeds PHP55,250 and the median age of the household members exceeds 26 years, the household is classified as using the SHS for lighting and its other uses. On the other hand, if the median age of the household members does not exceed 26 years but more than 21.5 or 22 years, then the household is classified as using the SHS for lighting only. If the median age of the household members is not more than 21.5 or 22 years, then the household is classified as using the SHS for lighting and its other uses.

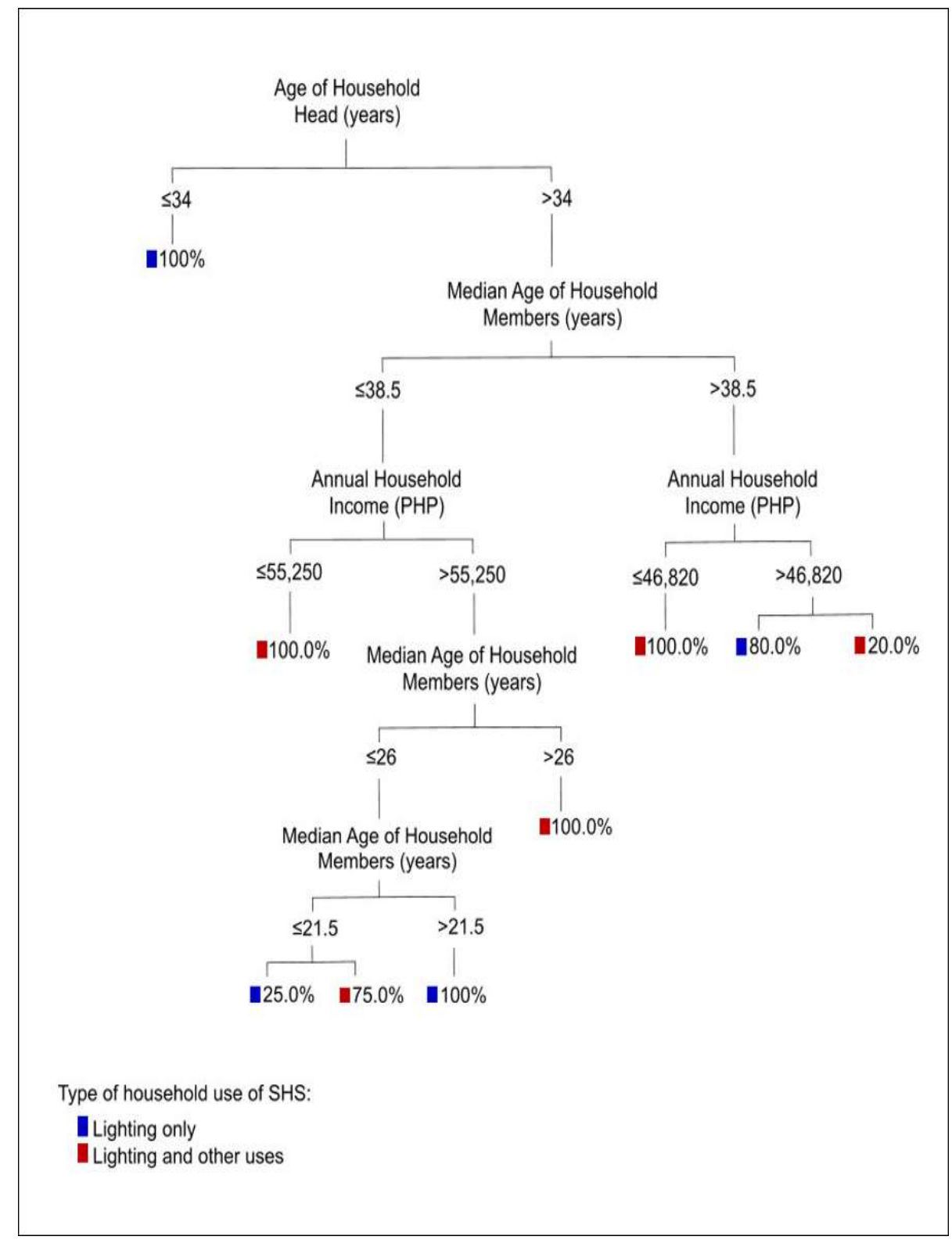

Figure 6. Classification tree on type of household use of the solar home system in Barangay Apid, Inopacan, Leyte 
Guarte, Maurillo \& Niverba

Application of the above decision tree to the Apid data resulted to a $95.7 \%$ correct classification rate of the households in the dominant group (using the SHS for lighting and its other uses) and an $88.9 \%$ correct classification rate of the households in the minority group (using the SHS for lighting only).

\section{Classification Tree on Type of Household Use of SHS in Dawahon}

In Dawahon, the complete data set $(n=97)$ has households using the SHS for lighting only not markedly dominating (55.7\%) over those using the SHS for lighting and its other uses (44.3\%). This is clearly indicative of a heterogeneous population. The best estimated model produced has a tree depth of 5 (Figure 7) with a $74.2 \%$ overall correct classification rate (risk estimate $=0.258$ with standard error estimate $=0.0359$ ). With four significant predictors identified by the estimated model, there are 9 splits and 10 terminal nodes in this tree. There are 5 paths or sequences of splits for a household to be classified or predicted as using the SHS for lighting only, and 3 paths for a household to be classified or predicted as using the SHS for lighting and its other uses. Given the high degree of heterogeneity at the root node, there are 2 paths for a household to be classified or predicted as either using the SHS for lighting only or using the SHS for lighting and its other uses. That is, there is no majority class or the plurality rule does not apply.

Household size has the most significant association with type of household use of the SHS. The other three useful predictors are annual household income, age of the household head and use of kerosene for lighting. The expected individual results from EDA on these four significant predictors as each relate to type of household use of the SHS are not directly observed in the estimated model as it is now the interplay among these four predictors that is shown in classifying the household into one of two categories of the response variable.

Based on the estimated model (Figure 7), if the household size is more than 6 and the annual household income is more than PHP60,000, then the household is classified as using the SHS for lighting only; if the annual household income is not more than PHP60,000, then the household is also classified as using the SHS for lighting only. Such split is performed because it leads to increased node purity (James et al 2013). Note that one is more certain of the household using the SHS for lighting only if the annual household income exceeds PHP60,000. If the household size is no more than 2 and the annual household income is more than PHP6,000, then the household is classified as using the SHS for lighting only. If the annual household income is not more than PHP6,000, then the household is classified as either using the SHS for lighting only or for lighting and its other uses. On the other hand, if the household size is more than 2, the household head is more than 59 years old, and the household uses kerosene for lighting, then the household is classified as using the SHS for lighting and its other uses. If the household does not use kerosene for lighting and its household size does not exceed 5 , then the household is classified as using the SHS for lighting only; if the household size exceeds 5 , then the household is classified as either using the SHS for lighting only or for lighting and its other uses. If the household head is at most 59 years old and the annual household income is more than PHP80,400, then the household is classified as using the SHS for lighting and its other uses; if the annual household income does not exceed PHP30,000, then the household is classified as using the SHS for lighting and its other uses. However, if the same household's annual income is 
Characterization and prediction of household use of solar

greater than PHP30,000 (but not to exceed PHP80,400), then the household is classified as using the SHS for lighting only.

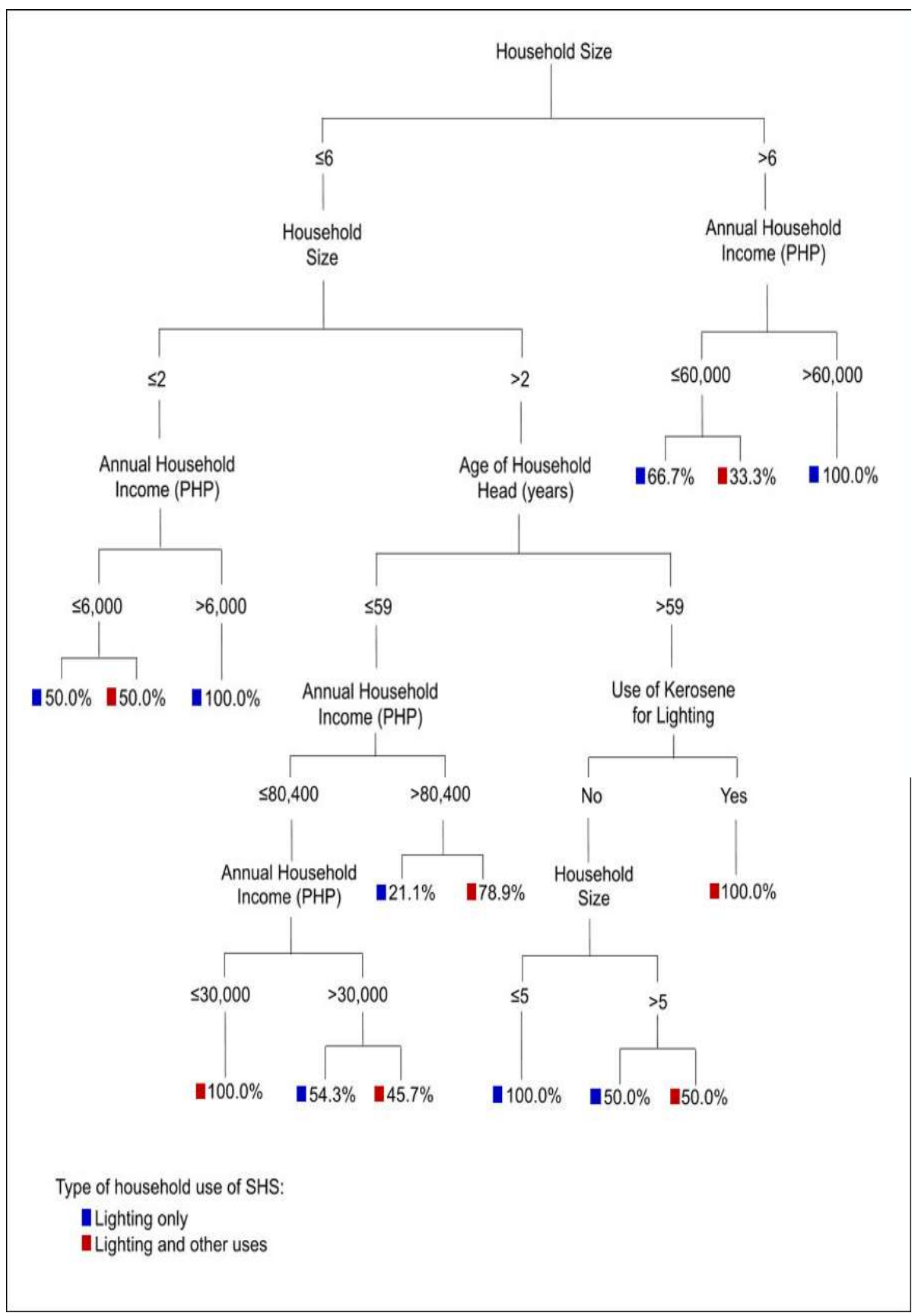

Figure 7. Classification tree on type of household use of the solar home system in Dawahon Island, Bato, Leyte 
Application of the above set of rules to the Dawahon data resulted to a $92.6 \%$ correct classification rate of the households in the larger group (using the SHS for lighting only) and a $51.2 \%$ correct classification rate of the households in the smaller group (using the SHS for lighting \& its other uses).

\section{Classification Tree on Type of Household Use of SHS in San Pedro}

In San Pedro, the complete data set $(n=85)$ has households using the SHS for lighting and its other uses dominating (67.1\%) over those using the SHS for lighting only $(32.9 \%)$. This indicates a relatively heterogeneous population. The best estimated model produced has a tree depth of 5 (Figure 8 ) with an $81.2 \%$ overall correct classification rate (risk estimate $=0.188$ with standard error estimate $=0.0193$ ). With the three significant predictors identified by the estimated model, there are 7 splits and 8 terminal nodes in this tree. There are 3 paths or sequences of splits for a household to be classified or predicted as using the SHS for lighting only, and 5 paths for a household to be classified or predicted as using the SHS for lighting and its other uses.

As in Apid, the age of the household head is also the most important predictor identified by the estimated model. This is followed by annual household income and median age of the household members. The expected individual results from EDA on these three significant predictors as each relate to type of household use of the SHS are not consistently translated in the estimated model as it is now the interplay among these three predictors that is shown in classifying the household into one of two categories of the response variable.

The estimated model (Figure 8) states that if the household head is no older than 52.5 or 52 years, then the household is classified as using the SHS for lighting and its other uses. If the household head is more than 82 years, then the household is classified as using the SHS for lighting only. Annual household income and median age of the household members can further predict the type of SHS use if the household head is older than 52.5 or 52 years but not more than 67.5 or 68 years. For such household, if the annual income is more than PHP78,000, then the household is classified as using the SHS for lighting and its other uses. If the annual household income does not exceed PHP78,000 and the median age of the household members does not exceed 38.5 or 38 years, then the household is classified as using the SHS for lighting and its other uses. However, if the median age of the household members exceeds 38.5 or 38 years, then the household is classified as using the SHS for lighting only. On the other hand, if the household head is older than 67.5 or 68 years but not more than 72.5 or 72 years, then the household is classified as using the SHS for lighting and its other uses. If the household head is older than 72.5 or 72 years (but not to exceed 82 years) with annual household income of no more than PHP10,800, then the household is also classified as using the SHS for lighting and its other uses. However, if the annual household income is more than PHP10,800, the household is classified as using the SHS for lighting only.

Application of the above decision rules to the San Pedro data resulted to an $89.5 \%$ correct classification rate of the households in the dominant group (using the SHS for lighting \& its other uses) and a $64.3 \%$ correct classification rate of the households in the minority group (using the SHS for lighting only). 
Characterization and prediction of household use of solar

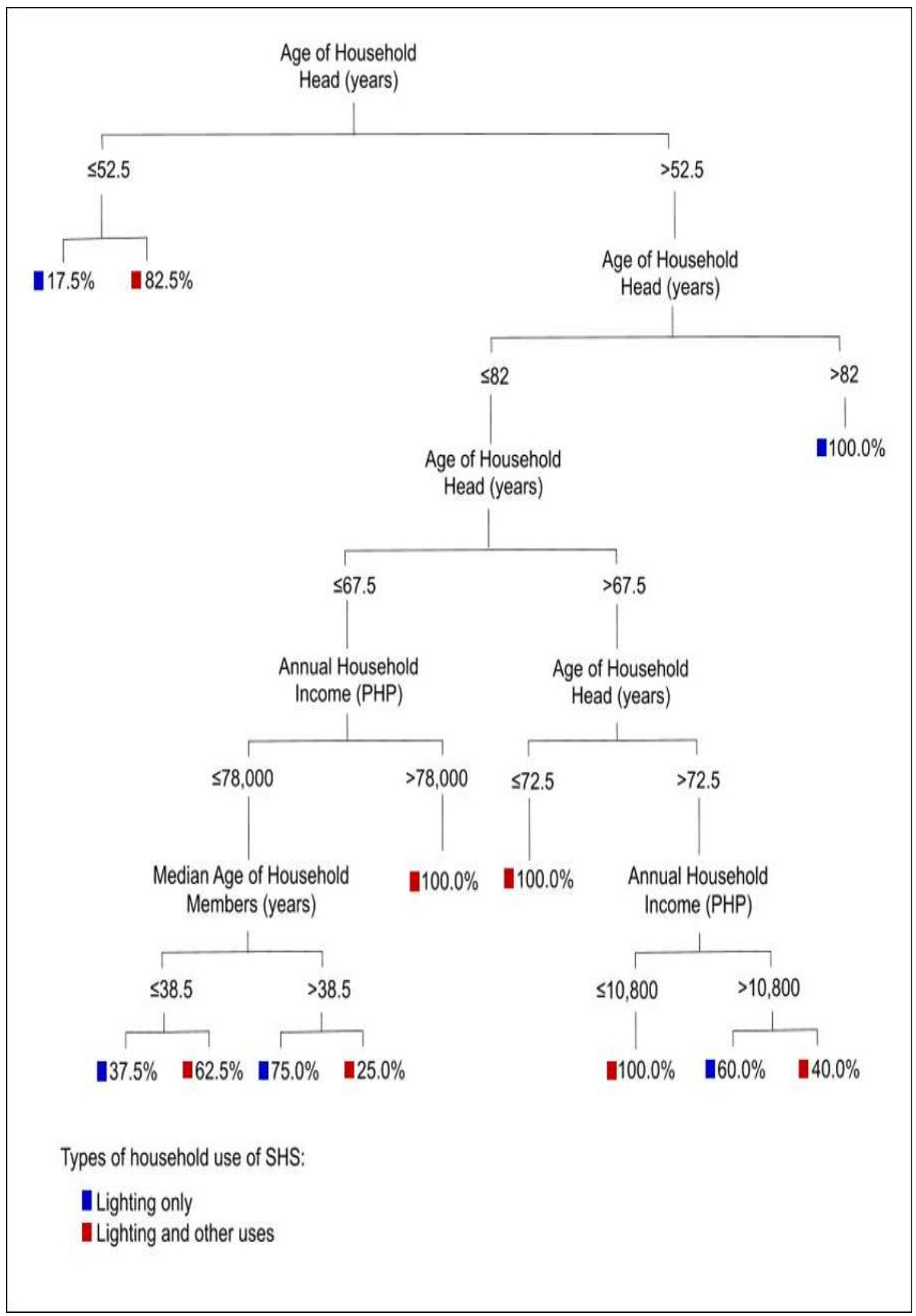

Figure 8. Classification tree on type of household use of the solar home system in San Pedro Island, Hinunangan, Southern Leyte 


\section{Classification Tree on Type of Household Use of SHS in San Pablo}

In San Pablo, the complete data set $(n=27)$ has households using the SHS for lighting and its other uses dominating (70.4\%) over those using the SHS for lighting only $(29.6 \%)$. This is indicative of a relatively homogeneous population. The best estimated model produced has a tree depth of 3 (Figure 9) with an overall correct classification rate of $88.9 \%$ (risk estimate $=0.111$ with standard error estimate $=0.0390$ ). With the four significant predictors identified by the estimated model, there are 4 splits and 5 terminal nodes in this tree. There are 2 paths or sequences of splits for a household to be classified or predicted as using the SHS for lighting only, and 3 paths for a household to be classified or predicted as using the SHS for lighting and its other uses.

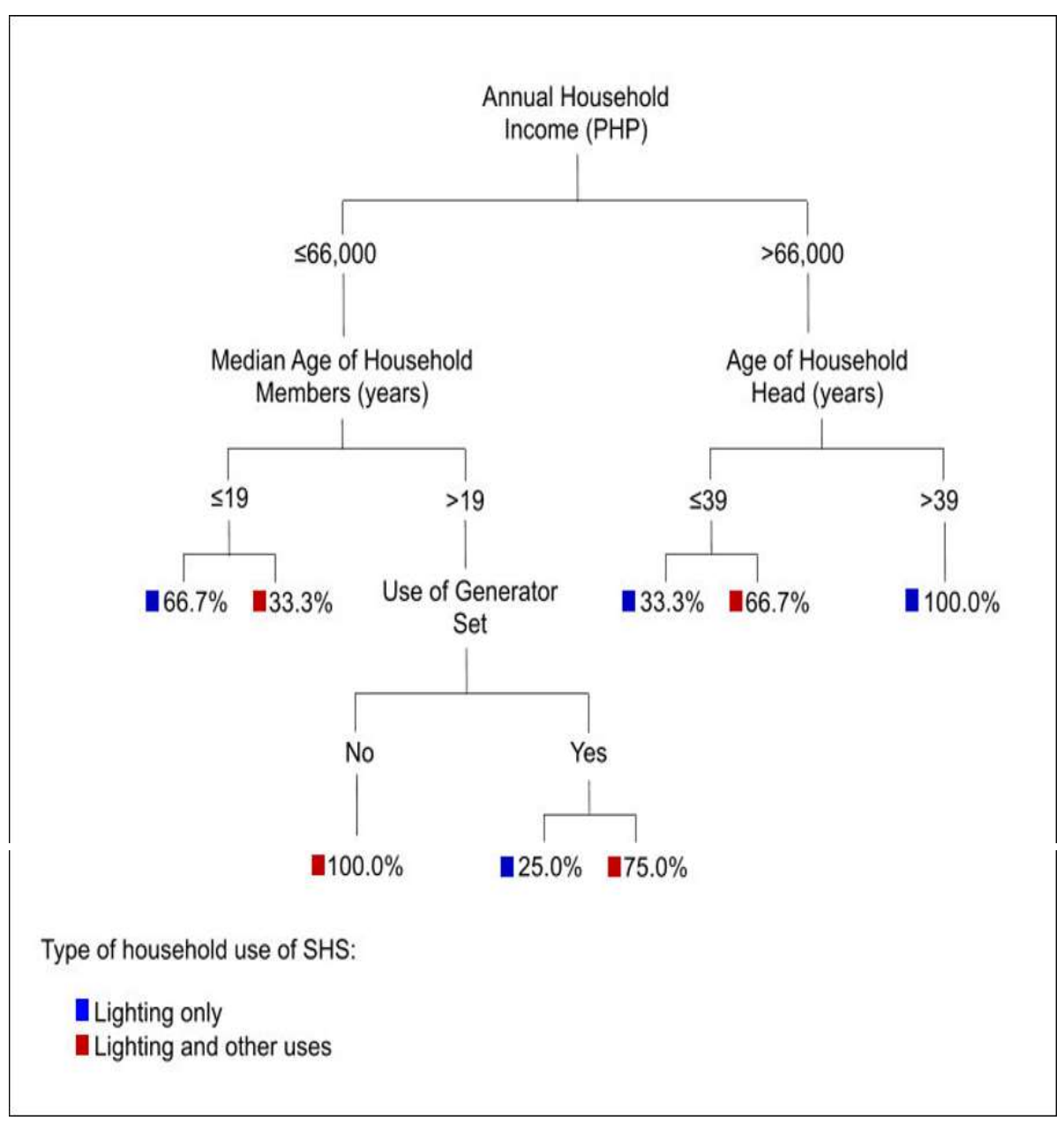

Figure 9. Classification tree on type of household use of the solar home system in San Pablo Island, Hinunangan, Southern Leyte 
Characterization and prediction of household use of solar

Annual household income is the most important predictor of type of household use of the SHS identified by the estimated model. The other three useful predictors are median age of the household members, age of the household head, and use of the generator set. The expected individual results from EDA on these four significant predictors as each relate to type of household use of the SHS are not consistently reflected in the estimated model as it is now the interplay among these four predictors that is shown in classifying the household into one of two categories of the response variable.

Based on the estimated model (Figure 9), if the annual household income is more than PHP66,000 and the household head is older than 39 years, then the household is classified as using the SHS for lighting only; if the household head is not older than 39 years, then the household is classified as using the SHS for lighting and its other uses. On the other hand, if the annual household income does not exceed PHP66,000 and the median age of the household members does not exceed 19 years, then the household is classified as using the SHS for lighting only; if the median age of the household members exceeds 19 years and the household does not use a generator set for electricity, then the household is classified as using the SHS for lighting and its other uses. If the household uses a generator set for electricity, then it is also classified as using the SHS for lighting and its other uses. The percentages at these terminal nodes, however, indicate that one can be more certain with the first classification.

Application of the above decision tree to the San Pablo data resulted to a $94.7 \%$ correct classification rate of the households in the dominant group (using the SHS for lighting \& its other uses) and a $75.0 \%$ correct classification rate of the households in the minority group (using the SHS for lighting only).

\section{CONCLUSIONS AND IMPLICATIONS}

There was a shift in household energy use for lighting with the advent of the $30 \mathrm{Wp} \mathrm{SHS}$ in the four island barangays studied. The dominant tandem of generator set and kerosene lamp is now replaced by that of generator set and SHS. With all household beneficiaries using the SHS daily and intensively for lighting, regular maintenance (cleaning \& care of the solar panel), prompt repair of the SHS when needed and access to SHS LED bulbs for replacement are critical for its sustainable use. The more lighting points a household has does not necessarily lead to the elimination of kerosene lamps. The continued use of the generator set (for a limited period) and kerosene lamp (mostly for overnight use in the bedroom) may indicate the need for larger-capacity SHS for total dependence on the SHS for lighting. This may also encourage increased level of utilization of the other SHS loads (particularly the radio) which can lead to improved well-being of the households through access to information (most importantly on health \& education) and entertainment. With almost all household beneficiaries using all four SHS LED bulbs daily, this number can be considered the minimum necessary for adequate home lighting in rural households.

The best classification trees grown indicate that the most common significant predictors (of whether or not the household will use the SHS not only for lighting but also for its other applications) in the four island barangays are age of the household head and annual household income followed by median age of the household 
members, based on the six predictors used. With the paths or sequences for a household to be classified or predicted of its type of SHS use unique to an island barangay, strategies directed at optimizing household benefits from this solar electrification program may consider the island barangay's best classification tree. In future modeling work, other potential predictors may be included like number of household members attending school (as they may use the SHS substantially for lighting and its other applications in relation to their school work the greater their number) and whether or not the household is engaged in livelihood activities (like having a retail store which may be operated in the evening using the SHS for lighting).

\section{ACKNOWLEDGMENT}

The researchers gratefully acknowledge the participation of Ms. Lara Nerissa G. Domanaco and Mr. Josef D. Poliquit in the conduct of the household surveys. The cooperation and assistance of the local officials and household beneficiaries in the island barangays of Apid, Dawahon, San Pedro, and San Pablo are deeply appreciated. Heartfelt gratitude is extended to Ms. Susana B. Miñoza for producing the needed figures. This paper comes from the study entitled "Operational Evaluation of Solar Home System Use by Household Beneficiaries in Leyte and Southern Leyte" under the project entitled "Socioeconomic Impact and Operational Evaluation of Renewable Energy Systems Installed in the Different Island Barangays in Leyte and Southern Leyte" with financial support from the Visayas State University, through the Regional Climate Change Research and Development Center and the Office of the Vice President for Research and Extension.

\section{REFERENCES}

Biermann E, Corvinus F, Hergberg TC \& Hofling H. 1992. Basic Electrification for Rural Households. GTZ, Eschborn

Buragohain T. 2012. Impact of solar energy in rural development in India. International Journal of Environmental Science and Development 3(4):334338

Chow JT. 2010. Assessment of solar home systems (SHS) for isolated rural communities in Vanuatu using project lifecycle/sustainability framework (MS thesis). Michigan Technological University, USA

Department of Energy (DOE). 2010. Energy Development Plan 2011-2016

Gustavsson M. 2007. With time comes increased loads-an analysis of solar home system use in Lundazi, Zambia. Renewable Energy 32(5):796-813

Islam Z, Shameem R, Mashsharat A, Mim MS, Rafy MF, Pervej MS \& Ahad AR. 2014. A study of solar home system in Bangladesh: current status, future prospect and constraints (pp110-115). 2nd International Conference on Green Energy and Technology, Dhaka

Izenman AJ. 2008. Modern multivariate statistical techniques: regression, classification and manifold learning. Springer-Verlag, New York

James G, Witten D, Hastie T \& Tibshirani R. 2013. An introduction to statistical learning: with applications in R. Springer Science+Business Media, New York 
Characterization and prediction of household use of solar

Kabir E, Kim KH \& Szulejko JE. 2017. Social impacts of solar home systems in rural areas: a case study in Bangladesh. Energies 10(10):1-12

Kamalapur GD and Udaykumar RY. 2011. Rural electrification in India and feasibility of photovoltaic solar home systems. International Journal of Electrical Power and Energy Systems 33(3):594-599

Khan SA and Azad AKMAM. 2014. Social impact of solar home system in rural Bangladesh: a case study of rural zone. IAFOR Journal of Sustainability, Energy and the Environment 1(1):5-22

Khan T, Hassan F \& Amin MK. 2018. The implications of solar home system usage for the rural communities in coastal Bangladesh. World Review of Business Research 8(1):12-25

Lohr SL. 2010. Sampling: design and analysis (2nd edn). Brooks/Cole, Boston

Meier P. 2003. Economic analysis of solar home systems: a case study for the Philippines. Asia Sustainable and Alternative Energy Program (ASTAE), World Bank, Washington, DC

Nieuwenhout FDJ, Van Dijk A, Van Dijk VAP, Hirsch D, Lasschuit PE, Van Roekel G, Arriaza H, Hankins M, Sharma BD \& Wade H. 2000. Monitoring and evaluation of solar home systems: experiences with applications of solar PV for households in developing countries. The Netherlands Energy Research Foundation ECN together with the Department of Science, Technology and Society of Utrecht University

Nieuwenhout FDJ, Van Dijk A, Lasschuit PE, Van Roekel G, Van Dijk VAP, Hirsch D, Arriaza H, Hankins M, Sharma BD \& Wade H. 2001. Experience with solar home systems in developing countries: a review. Progress in Photovoltaics: Research and Applications 9(6):455-474

Retumban KAM. 2015. Comparison of tree-based methods in identifying factors influencing credit card ownership and prediction accuracy. The Philippine Statistician 64(1):15-29

Samad HA, Khandker SR, Asaduzzaman M \& Yunus M. 2013. The benefits of solar home systems: an analysis from Bangladesh. Policy Research Working Paper no. WPS 6724. World Bank Group, Washington, DC

Stojanovski O, Thurber M \& Wolak F. 2017. Rural energy access through solar home systems: use patterns and opportunities for improvement. Energy for Sustainable Development 37:33-50

Villejo SJ. 2015. Classification and prediction of suicidal tendencies of the youth in the Philippines: an empirical study. The Philippine Statistician 64(1):35-43

World Bank. 2000. Zimbabwe - rural electrification study (English). Energy Sector Management Assistance Programme (ESMAP), no. ESM 228. World Bank, Washington, DC

Yaungket $\mathrm{J}$ and Tezuka T. 2013. A survey of remote household energy use in rural Thailand. Energy Procedia 34:64-72 